\title{
Human Capital Investment Model Based on Outsourcing Human Resources in Banking Industries
}

\author{
Widodo ${ }^{1}$, Sri Hindah Pudjiastuti ${ }^{1} \&$ Joko Bomber $\mathrm{SU}^{1}$ \\ ${ }^{1}$ Departement of Management, Islamic Sultan Agung University, Indonesia \\ Correspondence: Widodo, Departement of Mangement, Islamic Sultan Agung University, P.O.box 1054/SM, \\ Semarang, Indonesia. E-mail: widodo@unissula.ac.id
}

Received: February 5, 2018

doi:10.5539/ijbm.v13n9p236
Accepted: July 30, 2018

Online Published: August 7, 2018

\begin{abstract}
This article examines the human resource investment model based on outsourcing human resources in the Banking Industry. This study departs from the research gap, that is outsourcing system, where with this system, the company can save expenses in financing human resources (HR) working in the company concerned. However stated that the banking industry no more uses outsourced personnel in boosting the wheels of business. The complexity of the banking industry makes demands on the availability of high quality human resources (HR) increase. The findings of this study emphasized that in improving the efficiency and effectiveness of outsourcing based human resources on human resources investment is carried out by increasing the Human Resources (HR) cost efficiency. HR cost efficiency has indicators of the number of work completion with the time used is shorter than its standard, increasing the number of work completion with shorter time than its standard. And more completions work with standard time. While HR investment has the indicators of potential human resources as: developing, potential of HR excellence and quality of knowledge.
\end{abstract}

Keywords: training administration and recruitment activities, HR cost efficiency, HR Development, HR investment

\section{Introduction}

The existence of competition in the banking industry makes the company should concentrate on a series of process or activity of product creation related to its main competence. With the concentration on the main competence of the company, the number of good and highly competitive products will be produced. In a climate of increasingly tough competition, the banking industry seeks to improve efficiency of production cost. Outsourcing system is the answer, where this system can save the company in financing human resources (HR) working in the companies concerned (Ernesta Stasiulyte, 2011).

The study by Jirawuttinunt Sumittra (2015) showed that the dimension of outsourcing based human resources management includes recruitment activity, training and payroll management. Recruitment activity refers to the procedure of recruitment and transfer for selection activities to external providers. Outsourcing based recruitment activities includes advertising, hosting a job fair, searching for applicants and some selection processes, such as the selection of skill, organizations and backgrounds of applicants (Sethi, 2011). While training refers to the process of obtaining or allocating the knowledge, skills and competence to carry out specific competencies are useful for improving one's ability. Payroll management refers to the process of contracting with external businesses to regulate all or part of the work related to service compensation activities of human resources. The activities in concern include: payment of salaries, wages, bonuses, tax, and income cuts (Sumittra Jirawuttinunt, 2015).

The study By Jason D. Shaw. Tae Youn Park, and Euggene Kim (2013) suggested that the banking industry should stop using outsourced personnel in boosting the wheels of business. The complexity of the banking industry makes demands on the availability of high quality human resources (HR) increase. Therefore, banks are asked to dare to invest human resources for the improvement of service quality. The pattern of human resources recruitment in short term with outsourcing and contract system is considered as unsuitable for the resilience of the national banking system in the future. 


\section{Literature Review}

\subsection{Human Resources Management Investment}

Human resources are the human potential that can improve with a certain process such as educational process with a learning process. Investments are planting something to gain usefulness or benefit in the future. However, organizations face various challenges between to invest in human capital and how to retain its human resources. According to Jan M (2015), human resources differ in many aspects from other resources within the organization. Other resources except humans can be hired, retained and thrown away at any time, but human resources need special treatment. Other resources depreciates along with time, but human resources has more advantage, more experience, and more beneficial for organization. This characteristic has brought human resources to become a central element for the success of an organization.

The purpose of human resource development is to generate competence and qualified human resources, so they can perform the work assigned and contribute to organizational development and sustainable performance improvement. The quality of people working in an organization determines how good or bad the organizational tasks are achieved (Jason D. Shaw \& Tae Youn Park, 2012). Furthermore, it was also explained that the investment in the practice of Human Resources Management (HRM) will increase sustainable advantages. The practice of HRM is used as a tool to develop human resources and create a sustainable competitive advantage. Yet, if the organizations invest little in HRM, it will not improve the performance of human resources.

\subsection{Human Resources Cost Efficiency}

Providing competent resources is one of the most important issues in the organization because such condition affects future results. Shammy Shiri (2012) explains that the improvement of efficient human resource services leads to innovativeness. As its consequences, it can develop competitive advantage of organization to increase its capacity. Therefore, human resources in the organization must be managed effectively and efficiently.

Running an efficiency program is a time-consuming process until getting the best results. The results of the implementation of a new program often can be felt some time later to make many parties involved are reluctant to maintain commitment to run the program. The program efficiency requires high commitment, discipline, cooperation and perseverance of all parties involved to run a variety of programs selected. Even to run a variety of programs efficiency, the use of appropriate reward and punishment system needs to consider the program continuity. Sumittra Jirawuttinunt (2015) explained that the human resources cost efficiency refers to the ability of the company to complete the procedure in an effective cost with employee reduction.

The assessment of human resources efficiency is started with the process of recruitment, training, compensation and so on. The results of the study by Daniel (2012) stated that the indicators of human resources efficiency include: the number of work completion at the time used is shorter than its standard, increasing the number of work completion with shorter time than its standard and more completions work with standard time.

The study by Jirawuttinunt Sumittra (2015) showed that the HR cost efficiency has a positive impact on company performance. Outsourcing based human resources (HR) is driven by the company's continuous efforts to reduce costs and trigger competitiveness (Flora F.T. Chiang, Irene Hau-Siu Chow and Thomas A. Birtch (2010). Therefore, the hypothesis proposed in this research is:

H1: The better the human resources cost efficiency is, the better the human resources investment will be.

\subsection{Effective HR Development}

Human resource development is also an effective way to deal with some challenges, including obsolescence or lagging of human resources, diversification of domestic and international workforce. With affirmative and turnover action of human resources, the development of human resources can be maintained or sustained.

These challenges include human resource obsolescence, sociotechnical changes and employee turnover. The ability to overcome these challenges is a critical factor for the success of the personnel department in maintaining effective human resources. Development stands on the fact that an employee will need knowledge, skills, and abilities that evolve to work well in the succession of the position undertaken during his career. The long-term career preparation of an employee for this set of positions is what employees' development is about.

Development is more focused on the organization's long-term general needs. The results are indirect and can only be measured in the long run. Development also helps employees to prepare for changes in their jobs that can be caused by new technology, job design, new customers, or new product markets. Human resource development is considered to become even more important because of the demands of the job or position, as a result of technological advances and increasing competition among similar companies. Each personnel of the company is 
required to be able to work effectively and efficiently so that the quality and quantity of work can be better so that the company's competitiveness is greater and greater. This development is for non- career purposes and for employees through training and education.

An effective human resources development refers to the results of improvement or building competencies, skills and knowledge through training to improve performance (Sumittra Jirawuttinunt, 2015). HR effectiveness provides the significant added value of the organization (Cicek \& Ozer, 2011). A study showed that HRD activities have a positive impact on organizational performance (Jirawut Tinunt \& Janepuengporn, 2012). Thus, the higher the human resource development is, the more likely that the company will improve the performance and further adds value to an organization in the long term. The study by Hobana Karthikeyan and Manju Bhagat, NG Kannan (2014) explained that outsourcing based human resources have great potential for the organization's growth and sustainable competitive advantage. Therefore, the hypothesis proposed in this study is:

$\mathrm{H} 2$ : The more effective the human resources development is, the better the human resources investment will be.

\subsection{Outsourcing based Human Resources Management}

Outsourcing has become a common practice in Human Resource Management (HRM). Outsourcing identifies the contracting process with outsiders to perform the functions of human resource management or delivery of some activities of the company to other parties or function and service shift and the delegation of management to a third party (Hobana Karthikeyan, Manju Bhagat, \& NG Kannan, 2014).

Outsourcing activities have precondition which include: 1). Activities related to the strategic decision making which requires specialized management knowledge and activities that require confidentiality. 2). Understanding the advantages and disadvantages of outsourcing. 3). Creating effective relationship between outsourcer and sub-contractors doing the work (Donald L. Caruth, Stephanie S. Pane Haden, \& Gail D. Caruth, 2013).

Outsourcing cannot be considered as a short-term basis. By using outsourcing, organization can certainly spend more cost for outsourcing based company. Outsourcing should be viewed in the long term, ranging from career development of human resources in the field of employee, organization, and any other benefits efficiency. The company can focus on its core competencies in the business so that it can compete in the market, where the company's internal affiliation is transferred to a more professional party. In practice, this diversion also raises several issues, especially labor issues. The problematic on outsourcing varies. This is because the use of outsourcing increasingly widespread and has become a necessity that cannot be put off by businesses, while the existing regulations have not been too inadequate to regulate the outsourcing that has been underway. Outsourcing can allow the company to focus on its largest value creation activities and bring cost savings and operational flexibility. Hsi-An Shih and Yun-Hwa Chiang (2011) explained that outsourcing can offer training programs with higher quality and lower cost.

According to Sumittra Jirawuttinunt (2015), the activity of outsourcing based Human Resources Management (HRM) includes: recruitment activities, training administration and payroll management. Recruitment activity is the procedure for withdrawal and selection activities carried out by the service providers. Training administration is an allocation process of knowledge, skills and competencies that can improve performance. Payroll management is the contract process of HR providers with organizations with regard to compensation.

The study results by Seth and Sethi (2011) concluded that there is a positive correlation between outsourcing based recruitment and lowering the cost of human resources and the effectiveness of human resource development. Therefore, the hypothesis proposed in this study is:

H3: The better the outsourcing based HR is, the better the HR cost efficiency will be.

H4: The better the outsourcing based HR is, the more effective the HR development will be.

The study results by Chaudhuri and Bartlet (2014) showed that there is a correlation between Outsourcing based recruitment and lowering the cost of human resources and the effectiveness of human resource development. Therefore, the hypothesis proposed in this study is:

H5: The better the outsourcing based recruitment is, the better the the human resources cost efficiency will be

H6: The better the outsourcing based recruitment is, the more effective the human resources development will be. 


\section{Empirical Model}

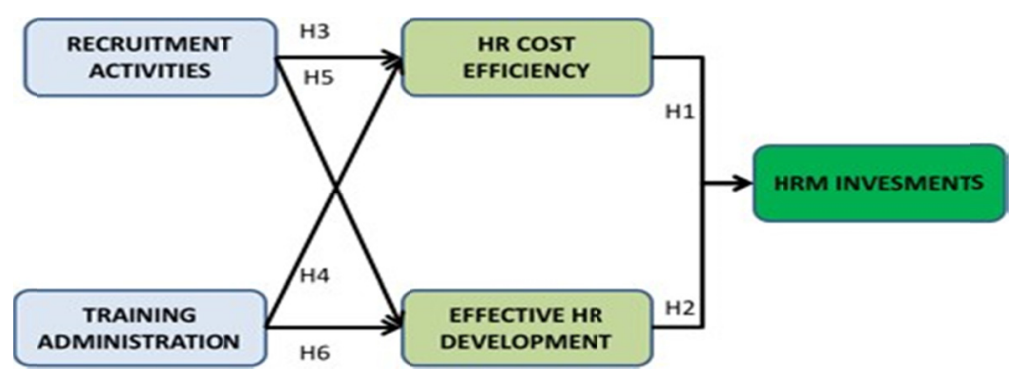

Figure 1. Empirical Model

The development model of outsourcing based human resources efficiency and effectiveness on human resources investment.

\section{Research Model Respondents}

The population in this study is the entire managers of the commercial banks and rural banks in the Central Jawa many as 330 managers (Bank Indonesia, 2017). By utilizing the model estimation of Maximum Likelihood (ML) with the magnitude of the respondent / sample size 100-200 (Hair, 1992), the number of samples in this study was 150 respondents.

\subsection{Variables and Indicators}

Table 1. Variables and Indicators

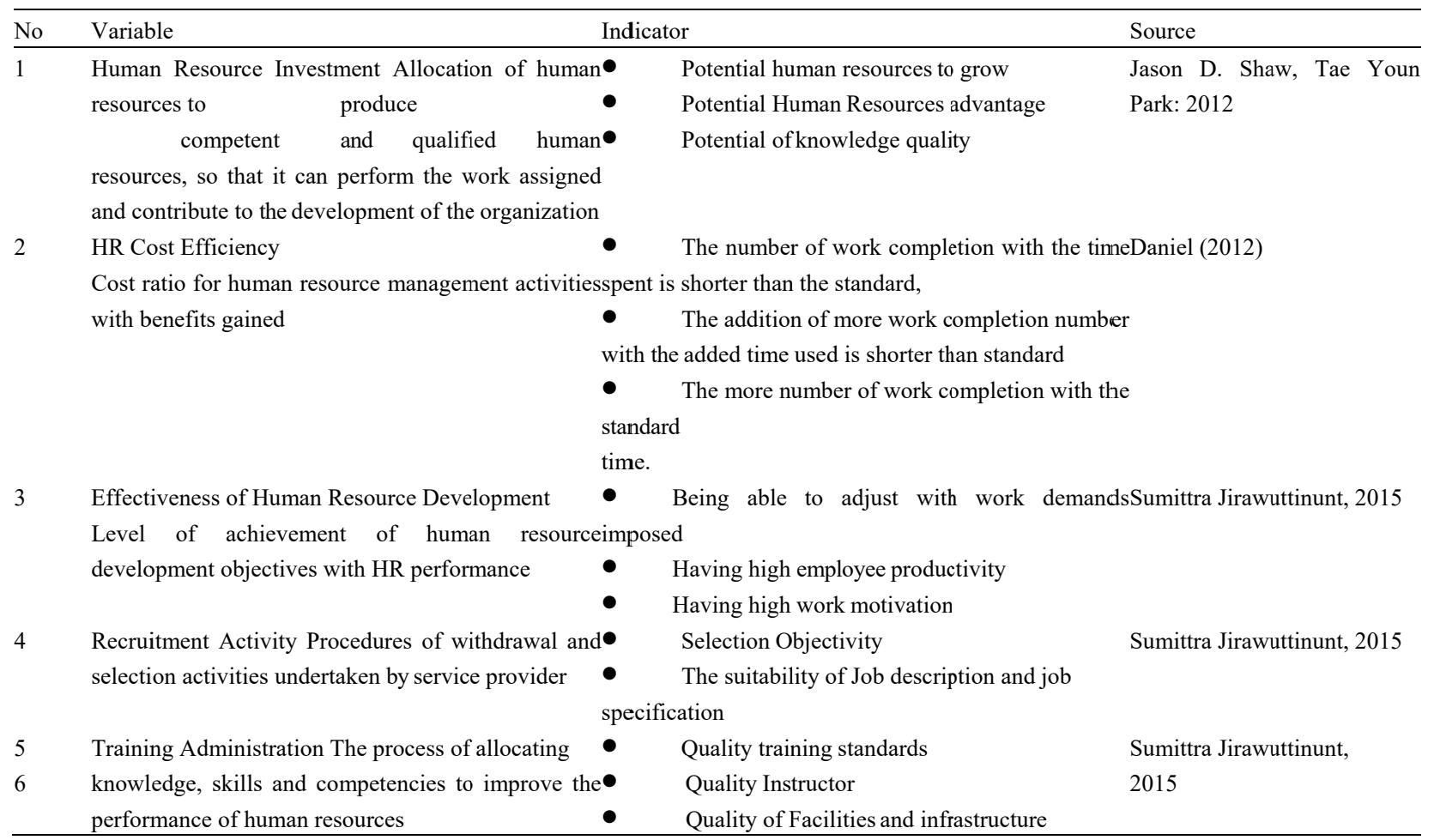

\subsection{Analysis Technique}

To analyze the data in this study, it was used The Structural Equation Modeling (SEM) of AMOS 5.0 software package. The steps in SEM, according to Ferdinand (2000), are as follows: 1) Developing model-based theory. 2) Developing Path diagram. 3). Evaluating Goodness-of-fit Criteria 4). In this step, the suitability of the model was evaluated, through review of the criteria of the goodness-of-fit. 


\section{Discussion}

Once the model is analyzed through a confirmatory factor, then each indicator in a fit modlel can be used to define latent constructs, so the full model of Structural Equation Model (SEM) can be analyzed. The results of analysis can be seen in Figure 2 and Table 2.

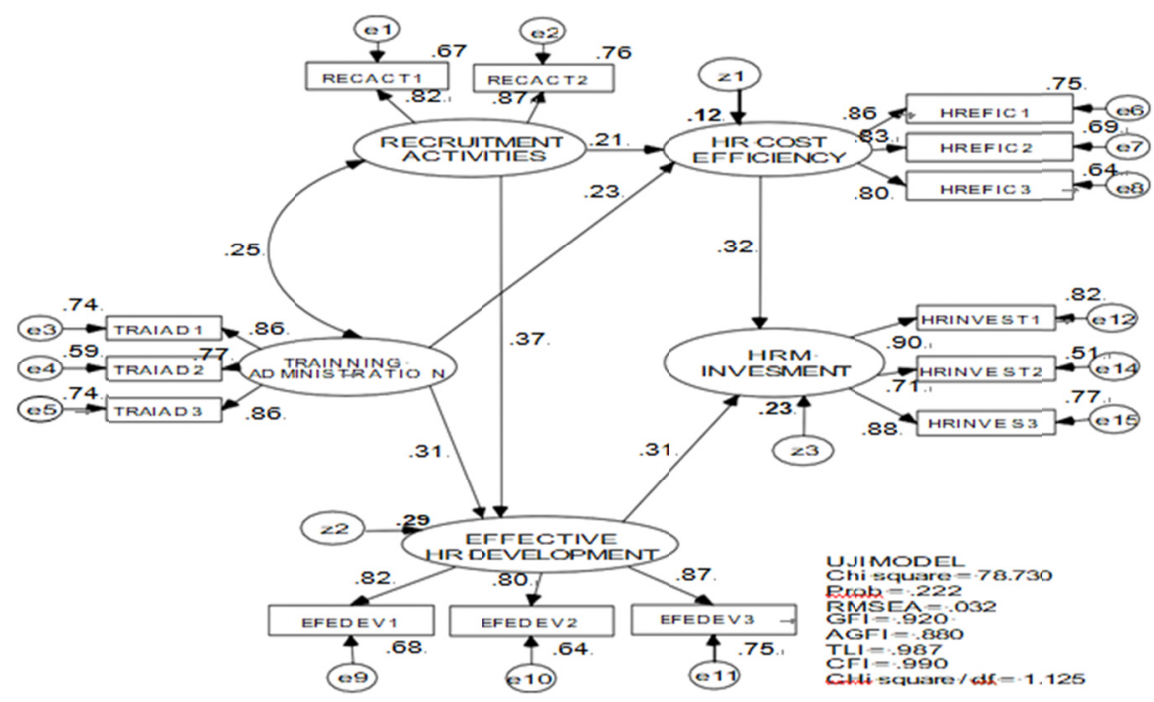

Figure 2. Full model human resources investment

Table 2. Standardized regression (Loading Factor)

\begin{tabular}{llllll}
\hline & & & Std.Estimate & S.E. & C.R. \\
\hline HR COST_EFFICIEN & $<-$ & TRAINNING_ADMINI & 0.231 & 0.092 & 2.198 \\
EFFECTIVE_HR DEV & $<-$ & RECRUITMENT_ACTI & 0.373 & 0.109 & 3.560 \\
HR COST_EFFICIEN & $<-$ & RECRUITMENT_ACTI & 0.212 & 0.106 & 2.063 \\
EFFECTIVE_HR DEV & $<-$ & TRAINNING_ADMINI & 0.306 & 0.091 & 3.093 \\
HRM_INVESMENT $<-$ - HR COST_EFFICIENCY & 0.317 & 0.110 & 3.231 \\
HRM_INVESMENT <- EFFECTIVE_HR DEVELO & 0.306 & 0.104 & 3.161 \\
\hline
\end{tabular}

The model test showed that this model is in accordance with the data or fit on the data used in the study. This is indicated by Chi-Square, Probability, CMIN / DF, TLI which were within the range of expected values despite GFI and AGFI marginally acceptable, it can be seen in Table 3.

Table 3. Test index of structural equation feasibility

\begin{tabular}{llll}
\hline oodness-of-fit-Index & Cut-off-value & Results & Information \\
\hline X-Chi-square & Expected small value & 78.730 & Good \\
Probability & $0: 05$ & 0.222 & Good \\
RMSEA & $0: 08$ & 0.032 & Good \\
GFI & 0.90 & 0.920 & Good \\
AGFI & 0.90 & 0.880 & Marginal \\
CMIN / DF & $2: 00$ & 1.125 & Good \\
TLI & 0.95 & 0.987 & Good \\
CFI & 0.94 & 0.990 & Good \\
\hline
\end{tabular}

Based on the calculation through confirmatory analysis and structural equation modell on Human Resources Investment, then this model is acceptable. Then, based on this fit model, it will be tested the hypotheses proposed in this early research. Presented in Table 1, it is shown that the six hypotheses are supported by empirical data with $\mathrm{CR} \geq \pm 2.00$ and a significance level of $0.05(5 \%)$. 


\subsection{The Effect of Human Resources Cost Efficiency on Human Resources Management Investments}

The first hypothesis proposed in this study is that the more efficient the human resource cost is, the better the HR investment will be. The variable of HR investment is built by the indicators: the potential of human resources to develop, the potential of HR advantages and potential of quality knowledge. While the human resources cost efficiency is constructed by the number of work completion with the time spent is shorter than the standard, the addition of more work completion number with the added time used is shorter than standard and the more number of work completion with the standard time.

The procurement of competent resource is one of the most important issues in the organization because such conditions affect future results. The improved efficiency of human resource services leads to innovativeness. As its consequence, it can develop a competitive advantage in organization to increase its capacity. As a result, the organization will have sustainable competitive advantage.

\subsection{The Effect of Effective HR Development on the Human Resources Management Investments}

The second hypothesis proposed in this study is the more effective the Human resource development is, the better the human resources investment will be. The variable of human resources investment is built by the indicators: the potential for human resources to develop, the potential of HR excellence and potential quality of knowledge. While human resources development is built by the indicators of being able to adjust with job demands imposed, having high productivity and high motivation

Anticipation of challenges and dynamics of the environment can be done effectively through developing human resources, including the obsolescence or underdevelopment of human resources, diversified domestic and international workforce. Through overcoming challenges and human resources turnover, the human resources development can be maintained or sustained. The human resources development stands on the fact that an employee will need knowledge, expertise, and ability which evolve to work well in the succession of the position undertaken during his career. The long-term career preparation of an employee for this set of positions is what employees' development is about.

\subsection{The Effect of Outsourcing based Human Resources Management on the Human Resources Cost Efficiency}

The third hypothesis set is the better the outsourcing (recruiting activity) of human resources is, the better the human resources cost efficiency will be. The variable of human resources cost efficiency is built by the indicators: The number of work completion with the time spent is shorter than the standard, The addition of more work completion number with the added time used is shorter than standard, The more number of work completion with the standard time. While outsourcing (recruiting activity) was built by the objectivity of the selection and the suitability of job description with the job specification.

The fourth hypothesis proposed in this study is that the better the administration training is, the greater the human resource cost efficiency will be. The variable of human resources cost efficiency is built by the indicators: The number of work completion with the time spent is shorter than the standard, The addition of more work completion number with the added time used is shorter than standard, The more number of work completion with the standard time.

Outsourcing have these characteristics: activities related to strategic decision making which requires specialized management knowledge and activities that require confidentiality, understanding the advantages and disadvantages of outsourcing, and creating Effective relationship between outsourcer and sub-contractor. as it Consequences, outsourcing offers a higher quality and lower cost training program.

\subsection{The Effect of outsourcing based Human Resources Management Outsourcing on Effective HR Development}

The fifth hypothesis proposed in this study is the better the outsourcing (recruiting activity) is, the more effective the human resources development will be. The variable of effective human resource development is built by the indicators: being able to adjust with job imposed, having high work productivity and motivation. While outsourcing (recruiting activity) was built the indicators of the objectivity of the selection and the suitability of job description with the job specification. The sixth hypothesis proposed is the better the administration training is, the more effective human resources development will be. The variable of effective human resource development is built by the indicators: being able to adjust with job imposed, having high work productivity and motivation. While the administration training is built by the indicators of the quality of training standards, the quality of instructors and the quality of facilities and the infrastructure.

The orientation of outsourcing is not only in the short term, but also long-term. By utilizing outsourcing, organization can certainly spend more cost for outsourcing company. Outsourcing should be viewed on a 
long-term basis, ranging from human resource career development, efficiency in the areas of employee, organization, benefit and others. The company can focus on its core competencies in the business so that it can compete in the market, where the company's internal affiliation is transferred to a more professional party.

\section{Conclusion}

Based on the results of empirical testing, the main priorities in improving the efficiency and effectiveness of outsourcing based human resources on human resources investment is conducted with increasing HR cost efficiency. HR cost efficiency has indicators of the number of work completion with the time spent is shorter than the standard, The addition of more work completion number with the added time used is shorter than standard, The more number of work completion with the standard time. While HR investment has the indicators of potential human resources as: developing, potential of HR excellence and quality of knowledge.

\subsection{Managerial Implications}

Based on the findings in this study, the model of outsourcing based human resources towards human resources investment in the Banking Industry in Semarang is as follows:

Investment is planting something to gain usefulness or benefit in the future. But then organization faces various challenges whether to invest in human capital or to retain its human resources. Such conditions make organization spends big amount of cost. Therefore, it must be done in a structured, systematic and sustainable manner.

The Increased human resource efficiency leads to innovativeness. As its consequences, it can develop a competitive advantage and improve the organization to increase its capacity. Therefore, human resources in the organization must be managed effectively and efficiently. By arranging the priority needs and the quality of human resources.

Human resource development should be based on the fact that human resources will require knowledge, skills, and abilities that develop in order to work well in a succession of positions undertaken during his career. The long-term career preparation of an employee for this set of positions is what employees' development is about.

The quality of recruitment activities should refer to the job analysis, which includes job descriptions whose contents relate to authority, responsibility, working conditions and structural relationships within the organization. Then, it is equipped with whom carries out the position, the key is the specification of positions related to the minimum requirements of office, such as level of education, experience, age and so forth.

The effective human resources development refers to the result of the development or building competencies, skills and knowledge through training for the purpose of improving performance.

\subsection{Research Limitations and Future Research Agenda}

Full SEM model test results show that the model is in accordance with the data or fit on the data used. However, there are two conformance tests received marginally namely the Adjusted Goodness of Fit Index (AGFI $=0.880$ ). This study focuses or departs from the phenomenon of internal conditions and research gap. The results of Squared Multiple Correlations are below $40 \%$. According to Klane (2002) the magnitude of $10 \%$ to $40 \%$ is in the medium criteria.

Organizational culture is a unified pattern of human behavior and related to the problem of adjustment or integration of internal and external conditions. Therefore, the organizational culture has a role in the development of human resources investment models based on outsourcing human resources. Thus, the study of organizational culture in the process of human resource investment is an interesting area to study.

In developed countries, the triggers of organizational performance improvement are generally dominantly sourced from internal conditions. However, in developing countries, external conditions (environment) dominantly influence the improvement of organizational performance. Environmental conditions include: 1). environmental complexity: it is the diversity of factors and problems that exist within the organization. 2). Environmental dynamics describes the degree of change that occurs in the environment in which the organization operates. Therefore, future research agenda needs to be considered.

Test results showed that it was still below $40 \%$. These conditions indicate that the relationship between variables is still in a black box and it needs further study.

\section{References}

Abdul Halim, H., \& Che-Ha, N. (2011). The perspective of Malaysian Manufacturing Organizations on Strategy, HR Outsourcing and HR Costs. Economia Seria Management, 14(1), 13-24.

Chaudhuri, S., \& Bartlett, K. R. (2014). The Relationship between Training Outsourcing and Employee 
Commitment to Organization. Human Resource Development International, 17(2), 145-163. https://doi.org/10.1080/13678868.2014.886444

Chowdhury, M. A., Yunus, M., Bhuiyan, F., \& Kabir, M. R. (2013). Impact of Human Resources Information System (HRIS) on the Performance of Firms: A Study on Some Selected Bangladeshi Banks. Proceedings of 9th Asian.

Cicek, I., \& Ozer, B. (2011). The Effect of Outsourcing Human Resource on Organizational Performance: The Role of Organizational Culture. International Journal of Business and Management Studies, 3(2), 131-144

Daniel, D. P. (2012). Eficiency of Human Resources Management in Railway Transport. Economics, Management, and Financial Markets, 7(4), 605-619.

Donald, L., Caruth, S. S., Pane, H., \& Gail, D. C. (2013). Critical Factors in Human Resource Outsourcing. Journal of Management Research, 13(4), 187-195.

Ernesta, S. (2011). Motives of Human Resource Management Outsourcing: a Case Study from Lithuania. Economics \& Sociology, 4(1), 116-125.

Flora, F. T., Chiang, I., Chow, H. S., \& Thomas, A. B. (2010). Examining human resource management outsourcing in Hong Kong. The International Journal of Human Resource Management, 21(15), 2762-2777. https://doi.org/10.1080/09585192.2010.528658

Gilley, K. M., Greer, C. R., \& Rasheed, A. A. (2004). Human Resource Outsourcing and Organizational Performance in manufacturing firms. Journal of Business Research, 3, 232-240. https://doi.org/10.1016/S0148-2963(02)00304-1

Hair, Jr. F., Joseph, R. E., Anderson, R. L., \& Tatham dan, W. C. B. (1992). Multivariate Data Analysis with Readings, Macmillan.

Hobana, K., Manju, B., \& Kannan, N. G. (2014). Examining Human Resource Management Outsourcing in India, International Journal of Business Insights and Transformation, 7(1).

Jan, M. A., \& Abdul, W. (2015). Importance of Human Resource Investment for Organizations and Economy: A Critical Analysis. Journal of Managerial Sciences, 7(1).

Jason, D., Shaw, T. Y. P., \& Euggene, K. (2013). A Resource Based Perspective on Human Capital Losses, HRM Invesments and Organizational Performance. Strategic Management Journal Strategic, 34, 572-589. https://doi.org/10.1002/smj.2025

Jirawuttinunt, S., \& Janepuengporn, K. (2012). Effects of human resource development activity effectiveness on business performance of jewelry and gem businesses in Thailand. Journal of Academy of Business and Economics, 12(5), 181-197.

Seth, M., \& Sethi, D. (2011). Human resource outsourcing: An analysis based on literature review. International Journal of Innovation, Management and Technology, 2(2), 127-135.

Shammy, S. (2012). Strategic Role of HR Audit in Organizational Effectiveness. Journal of Management \& Public Policy, 3(2).

Shih, H. A., \& Chiang, Y. H. (2011). Exploring the effectiveness of outsourcing recruiting and training activities, and the prospector strategy's moderating effect. The International Journal of Human Resource Management, 22(1), 163-180. https://doi.org/10.1080/09585192.2011.538980

Widodo. (2015). Strategic Knowledge with Strategic Alliance Based to Achieve a Sustainable. International Journal of Economic Cooperation and Development, 36(2), 35-62.

Widodo. (2015). The Development Design of Knowledge quality Based on Knowledge networking and Cross Functional Integration toward SMES' Innovative Performance. Journal of Applied Economic Sciences, 8(38).

\section{Copyrights}

Copyright for this article is retained by the author(s), with first publication rights granted to the journal.

This is an open-access article distributed under the terms and conditions of the Creative Commons Attribution license (http://creativecommons.org/licenses/by/4.0/). 